\title{
TRABASA - TRADITIONAL ARCHITECTURE RECORDED BY MEANS OF BUILDING ARCHAEOLOGY IN SAUDI ARABIA: WORKSHOP IN JEDDAH
}

\author{
U. Herbig ${ }^{\text {a }}$, C. Jäger-Klein ${ }^{\text {a }}$, I. Mayer ${ }^{\text {a }}$, H. Mortada ${ }^{\text {b }}$, G. Styhler-Aydın ${ }^{\text {a }}$
${ }^{a}$ Vienna University of Technology, Department for History of Architecture and Building Archaeology, Vienna, Austria, E251.sekretariat@tuwien.ac.at Jeddah, Saudi Arabia, hmortada@kau.edu.sa \\ ${ }^{\mathrm{b}}$ Department of Architecture, Faculty of Environmental Design, King Abdul Aziz University,
}

Commission V, WG V/2

KEY WORDS: Training, Methods of Building archaeology, Documentation of traditional architecture, Survey of Arabien architecture, Cultural heritage of Jeddah, University cooperation

\begin{abstract}
:
Saudi Arabia has a rich architectural heritage that can be found in all regions of the vast country. Except for a small number of publications the recording and documentation of the traditional built environment was not content of detailed scientific investigations so far. But with the increasing decay of the architectural heritage the interest for this kind of research is rising. A mirror of this efforts is the National Built Heritage Forum, annual conference, launched in 2010 by his excellency Prince Sultan bin Salman bin Abdulaziz Al Saud and the Saudi Commission for Tourism and Antiquities (SCTA). In that frame Saudi universities are intensifying research and educational programs for the research of traditional architecture.

In 2008 the Department of Architecture of the College of Environmental Design at the King Abdulaziz University established a cooperation with the Department of History of Architecture and Building Archaeology of the Vienna University of Technology with the aim to start an exchange of knowledge and experience in building archaeology and building survey. An important part of this cooperation was a workshop for staff and students in the historic centre of Jeddah. The aim was to train methods and techniques on typical examples in the old town of Jeddah, Al Balad. This paper is describing the layout of the workshop, the process of the work and examples of the results.
\end{abstract}

\section{INTRODUCTION}

The Department for History of Architecture and Building Archaeology, at the Vienna University of Technology (VUT) is working on the recording and documentation of architecture in research and education for many years. One important topic is the knowledge transfer of approved methods for the interdisciplinary work. In this frame a course program has been developed for the cooperational work with other universities.

In this paper we will describe the workshop in Jeddah / Saudi Arabia as an example for the transnational interdisciplinary work for the documentation and investigation of traditional built heritage.

The very rich and diverse architectural heritage of Saudi Arabia is highly endangered. Economic and social conditions lay the base for a focus on modern architecture. Traditional construction methods and designs are sparsely used, mostly just as reminiscence with no detailed reflection. Still existing structures are either ignored or completely converted in a way that not much is left from the original substance. So far the discussion about the values and sustainable use of traditional Saudi Arabien architecture is at its beginning.

In that frame the cooperation with the Department of Architecture at the Faculty of Environmental Design, King Abdul Aziz University in Jeddah (KAU) was started with a fieldtrip to the traditional architecture of western Saudi Arabia. Following, a research project was established on "Documentation and Analysis of Traditional Domestic Architecture of Saudi Arabia". Part of this project was a four week collaborative workshop TRABASA - Traditional Architecture recorded by the means of Building Archaeology in Saudi Arabia - held in October in 2011 by members of VUT. The workshop was designed as training for staff and students of the KAU to conduct a detailed building survey of the traditional architecture in the historical district Al Balad in Jeddah.

\section{THE WORKSHOP}

The workshop was dealing with living heritage defined in detail as a type of Saudi traditional architecture found in cities, centres of cities, or/and districts of cities, where inhabitants live their daily life in traditional buildings. The documentation covered three scales: urban (city), local (neighbourhood), and architecture (buildings). A comprehensive literature review completed the field survey. In the case of Jeddah, where the urban scale is large, an action area was selected documented at the three mentioned scales. In addition to the urban and architectural characteristics like design and construction materials and techniques, historic, environmental and social aspects were studied.

\subsection{Organisation of collaboration on site}

One geodesist, five architects and one cultural anthropologist formed the VUT team. The work on site was organised in weekly tasks. According to the topics the seven members of the VUT stayed at Jeddah alternately.

After the first week with a theoretical introduction by the VUT team the plan was to work in teams with representatives of the 
18 staff members of the KAU team supervising in collaboration 45 students of architecture, geomatics and landscape planning.

At the town hall of the historic part of Jeddah, called Al Balad offices were provided as working space for the group. Besides the perfect location of the Baladia (the town hall) in the centre of Al Balad, the group was supported by the major of Al Balad and his staff in practical matters as well as through the provision of important local data and information.

The cooperation with the geomatics department from the KAU regarding the use of equipment was positive and it was helpful to employ also the equipment of the KAU for the amount of recording and training the large number of students.

Practical work was assigned to the whole team on a daily basis via email, so that in spite of teaching and studying commitments of the KAU members everybody was informed and had the chance to attend. Daily working hours were held as long as possible. The team usually stayed in and around the houses during daylight hours and used the evenings and weekends to prepare for oncoming working phases. At a later stage, drawing and office work was carried out in small teams also in the Baladia.

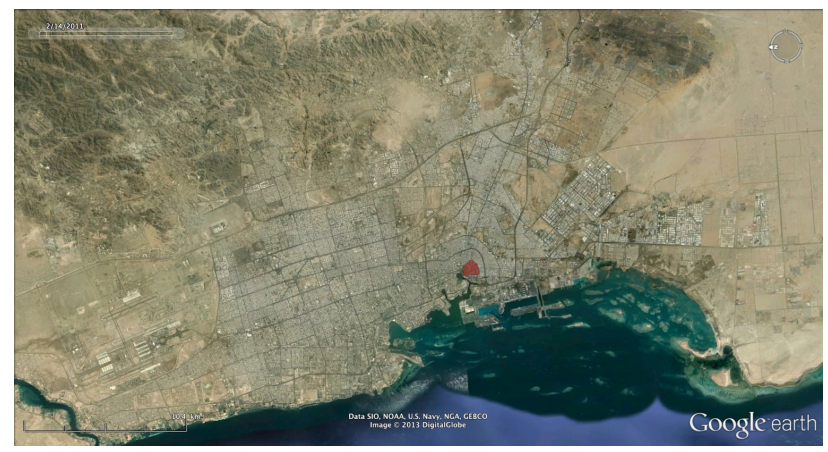

Figure 1, Old Jeddah (red) in the centre of modern Jeddah

For the workshop the area within the boundaries of Al Balad was selected for the research at urban scale. The detailed building survey was realised in a house situated close to the Baladia, named Al Nawar House. These records were accompanied by a rough survey of one of the most well known buildings of Old Jeddah, the Noor Wali House. According to this choice the area including Al Nawar House, Naseef House and Noor Wali House was the place for work concerning the neighbourhood scale.

\subsection{Training and Education:}

Building archaeology is an interdisciplinary task best carried out in teams, as different approaches provide a wider and more detailed result for the analysis. Surveying, drawing and analysing need practical experience and provide the base for the detailed research and the understanding of the building, its construction and its history. Research methods needed for building archaeology can only be learned and also trained on the object. The following skills were trained:

Survey of different topics, collecting of data, focussing on problems and potentialities and elaboration of data at an urban level (city analysis).

- Survey with the total station, which could be described as successful as the students could do jobs on their own after the introduction and supervised first jobs.
Survey with the 3D laser scanner. It was done in two groups, one with the VUT instrument; the other with the scanner of KAU. Both teams worked individually after introduction and first supervised jobs. The outcome measured with the VUT instrument was started to be post processed on site with an introduction into this procedure for the students.

Production and use of orthophotos. Because of the time consuming work of providing the geometric information the time for the rectification training was short and will need improvement.

- Drawing skills and the use of existing plans for revision. This was an important training for the students in case there are plans available for historic buildings, which have to be interpreted and compared with the real situation very carefully. Existing plans are a source to trace the history of the building and can give various information.

Standards of detailed photo documentation.

- Configuration and use of the room book and catalogues (e.g. the catalogue of openings, the catalogue of features, the catalogue of construction materials, the catalogue of damages) .

\subsection{Topics of the workshop in detail}

Theory: The theoretic lectures gave an introduction into topics like the importance of the recording, documentation, research and building archaeology for the preservation and the future development of the architectural cultural heritage:

- Categories and definitions of traditional architecture, vernacular architecture, industrial heritage, national and religious monuments, ensembles, heritage at risk, heritage and tourism.

- Recording and documentation of the world heritage, The World Heritage Convention, The World Heritage List, nomination process, advisory bodies, reporting. Documentation and inventory: Building survey in general, methods, purpose and base for further research, art and architecture topographies, as an Austrian example Georg Dehio and his handbooks, modern data base, European model of inventory and the role of universities within, research options in the field of history of architecture.

- Qualitative research methods of Cultural and Social Anthropology for studies in architecture. Advantages of such an interdisciplinary approach, the fieldwork situation, ethnographic quality, the question of objectivity, trust building measures, interview techniques and the interpretation and analyses of the field data.

- Protection and care of monuments: History and theory, recent developments within Europe and the world; World heritage, status, organisation, charters of UNESCO and ICOMOS, status quo and structure of organisations within Austria as an example; Recent issues discussed like contemporary architecture and heritage.

- Adaptive reuse: Analysis of function, material, construction, urban context; Reflection on regional climatic as well as social and cultural conditions; Translation into future design strategies; Interaction and cooperation between universities, federal institutions, politics, private clients.

City Analysis: The city analysis focused on getting in touch with the historic city of Jeddah. Most of the participants had 
never entered Old Jeddah before. Al Balad has a very bad reputation in amongst the citizens of Jeddah for being a very dirty place, where just poor foreign people are living and the crime rate is very high. Besides that the KAU members never participated in an on-site workshop with collecting and elaborating data directly on site. Students started the city analysis with exercises focused on the cataloguing of data. During this first step that only requires observation skills some students showed good results. The second step of the analysis concerned a critical elaboration of the data in order to produce a subjective statement on the observed problems and potential of the city. This step required developed analytical skills, ability for a systematic comparison between similar cases (even inside the city itself), interdisciplinary approach and autonomy work.

Recordings: The goal for the workshop was the training of a complete, contour-accurate survey and analytical documentation to be summarised as building archaeology of an object. The documentation of the building takes place by means of a complete survey, in drawings and photographs of all the components of the building, subsequent cataloguing of all parts of the building, and indexing of the analysed structural phenomena. Combining digital and manual architectural measurements, the VUT team employs a particularly flexible and non-tactile method of surveying.

The total station employed in the workshop by VUT was the motorised tachymeter Leica TCRM 1203+ in combination with the software "TOTAL" (Tachymetric Object-Oriented Semi Automated Laser Measurement), which enhances the total station into a so-called "intelligent tachymeter". A particular feature here is the combination of a tachymeter's precise accuracy and the advantages of automatic scanning processes, which is employed specifically with "profile scanning", a process that delivers the base for contour-accurate architectural sections through the building (e.g. horizontally and vertically for floor plans and sections). With the use of the total station polygon tracks around the Al Nawar House and points in the Noor Wali House were measured to deliver spatial information as a base for the object integration. Furthermore, the instrument was used to measure registration points for the laser scanning and for processing orthophotos. The floor plans of levels $0,1,2$, 3 as well as one vertical section of the Al Nawar House were measured using the software TOTAL. This work was mainly carried out by students after intense introduction to the use of the instrument and the basic principles of surveying. Additionally, two total stations Leica TPS $1200+$ from the KAU were available.

The 3D laser scanner employed in the workshop was the terrestrial 3D-Image-Scanner $\mathrm{Z}+\mathrm{F}$ Imager $5006 \mathrm{i}$ by the company Zoller \& Fröhlich. During the scanning process, continuous three-dimensional point clouds were made of large parts of the building. These were then assembled to create a digital 3D model, the starting point for the scaled drawings. For the Al Nawar House this technique was used to survey the rooms along the longitudinal section by the VUT team together with KAU students and rooms along a vertical section by the KAU team, to record the façades of the building and the interior design of the most interesting rooms. After the intense training at the Al Nawar House, the student's team scanned the north facade of the Noor Wali House and three rooms on the 4th floor of the house quite independently. For the purpose of training a Leica ScanStation C10 from the KAU was employed as well.

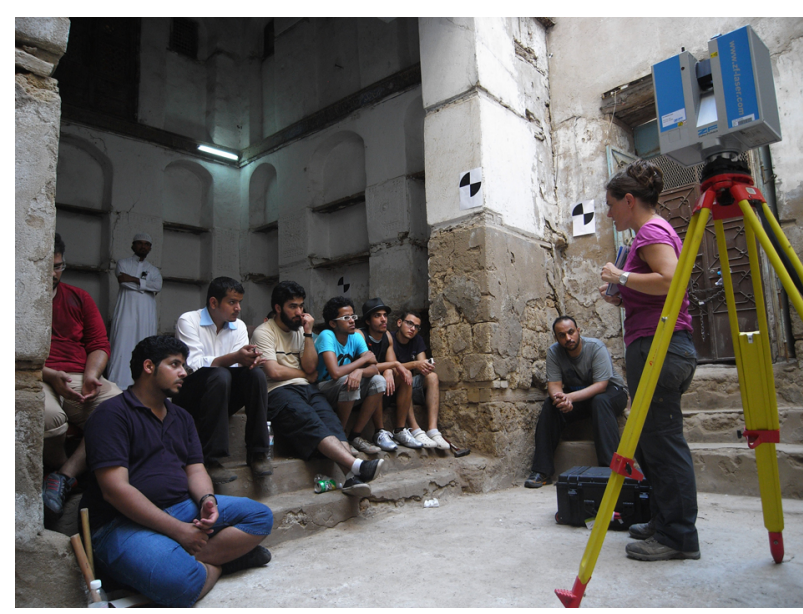

Figure 2, Introducing the Z+F Imager 5006i

The production of wall plans is based on pictorial information as well as digitally measured data. In more extensive view areas, orthophotos provided the basis for drawings. The VUT team introduced the method also to the students.

For the Noor Wali House orthophotos were computed as a base for the mapping of ornaments, construction materials and damages.

Drawing of the buildings was based on the digital surveying framework. The drafts generated from digital data were evaluated by the building archaeologists, and completed to create contour-accurate architectural drawings. The survey of the buildings also includes drawings of constructive and architectonic details on scales ranging from 1:1 to $1: 10$. The overall view of the Al Nawar House emerges in a set of plans encompassing all the horizontal and vertical sections and elevations necessary for its interpretation.

For the Al Nawar House the plans of all floors were drawn on site. The drawing of the sections was started on site and was completed by the VUT team back in Vienna using the measurements, pictures and scans taken on site. At the Noor Wali House students under supervision revised existing drawings. Furthermore drawings of all categories of openings in the Al Nawar House and two rooms at the northwest corner on the 4 th floor of the Noor Wali House were made.

Parallel to the registration in drawings, the entire building of the Al Nawar family and the documented rooms at the Noor Wali House were photographed and the present state of preservation documented.

The cataloguing of the different categories of openings of the Al Nawar House was started on site by students and was completed by the VUT team in Vienna. This is a part of the room book, which also includes:

- Building parts catalogue for a systematic recording of all building parts and their design details

- Material catalogue: construction materials used, with synopsis for the entire building

Catalogue of characteristics: structural, construction and design characteristics specific to the object as preparation for an overall object comparison

The indexing of structural findings, phases of the building process and of damages was conducted based on the mapping made on site by the VUT team. 
The building analysis was started on site with a structural analysis and a functional analysis concerning building organisation, logistics, capacity, equipment and altered demands. First findings were presented and discussed and became the base for further analysis by the VUT team.

Discussions about potentials of the built heritage of Old Jeddah, considering the historic town not as a problem, but as a resource to be conserved for future generations were an important part during the workshop. Especially facing the fact that history of architecture and existing building structure is not part of the curriculum at the KAU at the moment the interest and ideas of the students have been very interesting and showed potentials for the future.

Filming: The aim of the film was to summarise the workshop and to document the process of the training. Students and staff members carried out the filming. A short summary of the work was presented at the final presentation in the Naseef House. VUT team compiled a more detailed documentary.

\subsection{Schedule of the workshop}

The first week's main issues were introductory meetings of the VUT and KAU teams and organisational matters. Discussions of the researchers were focussed on future strategies of $\mathrm{Al}$ Balad. Introductory lectures were given by the VUT team to prepare for the work. This theoretical input included many aspects of the preservation and documentation of the built heritage: theoretical classifications of built heritage and heritage organisations, social anthropological investigation, introduction to practical research work and also examples of projects that were carried out by the VUT team in other countries like for example Azerbaijan, Afghanistan or Egypt.

Another important issue of the first week was the organisation and designation of the study sites. For the city analysis at large scale the boundaries of Al Balad were defined. At the level of neighbourhood studies an area around the Baladia was outlined after the selection of the objects for the building survey. For the detailed analysis the Al Nawar house was selected as an example of the home of a common family. The Noor Wali house was selected as outstanding example of a wealthy merchant family. As this building is very large its detailed survey would have been gone beyond the scope of the workshop. So this object was used to do an exemplary study in revising existing plans and a detailed photo documentary.

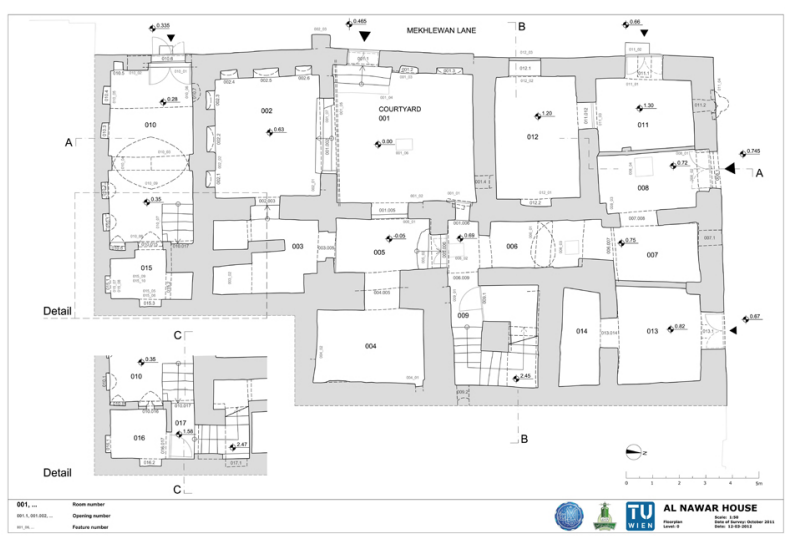

Figure 3, Floor plan Al Nawar house
The largest scale of research, city analysis, started parallel right at the beginning of the workshop. Specific research tasks were given to groups of students to investigate on contextual issues of Al Balad. During the time of the workshop the students could work on these tasks besides building survey.

The second week was characterised by the introduction into the practical work on site after the transfer of equipment to the Baladia and the formation of the supervising teams.

Building surveying started in two major groups. The architects began with the production of sketches of the floor plans. Based on the floor plan of level 0 produced by VUT the other sketches of floor plans and the sections where compiled in groups. This laid the base to prepare the geometric information within and around the building.

The KAU geomatics group was introduced to the total stations. Thereafter they started surveying traverses around and in the Al Nawar House to prepare a grid of spatial information. Coordinates of reference points were measured with GPS in order to transfer the locally defined house coordinate system into a regional system also used by the municipality.

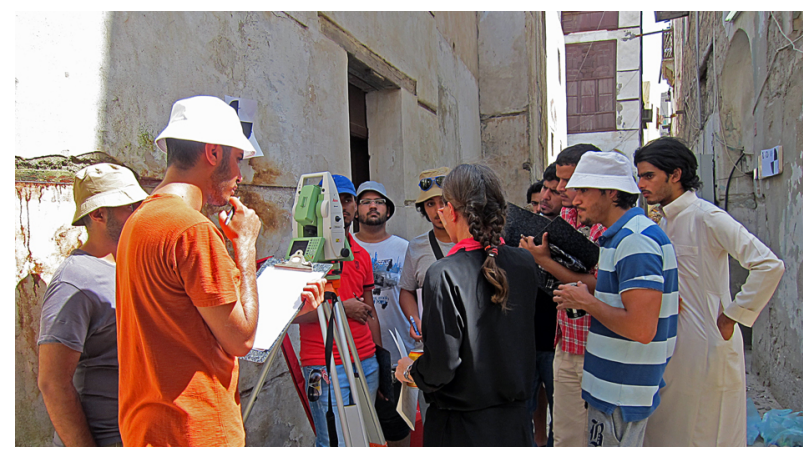

Figure 4, Introducing the total station

A detailed collection of openings and photographic wall documentation was started. For relating photographic information with three-dimensional data nearly every single wall surface of the house was tagged with target points. These targets were measured to provide information for the rectification of the pictures within the local system.

Parallel to the recordings of the Al Nawar House and guided by the VUT team, a small group of students started the rough survey of the Noor Wali House. This included detailed recording of the roshans (the wooden openings) and wooden walls, done manually, and the review of existing floor plans.

In the third week $3 \mathrm{D}$ laser scanning was introduced and processing of the information started. 3D scans were carried out in the main spaces of the Al Nawar house. After the presentation of the software "TOTAL" (Ruhr University Bochum: http://www.ruhr-uni-bochum.de/geodaesie/ftotal.html ) the students rectified the images of the walls. These were used to map damages, ornaments and material. 


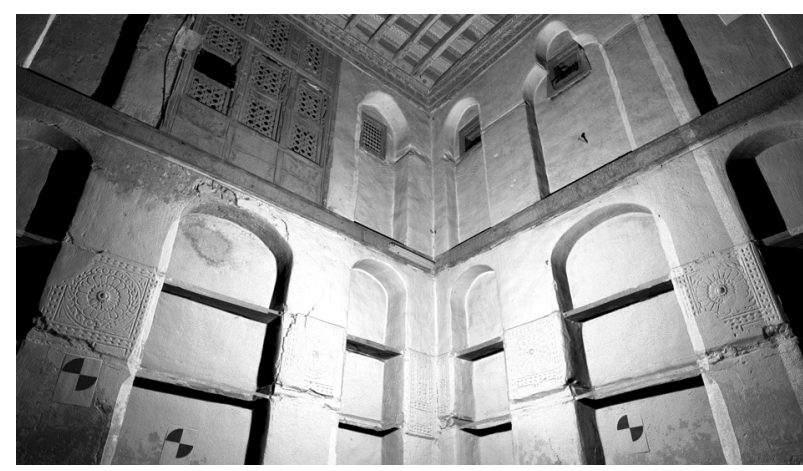

Figure 5 3D Laser scan of the Al Nawar house

Parallel the floor plans and sections of the Al Nawar house were prepared based on the tachymetric and 3D survey including the study of the details. This work has to be started on site for a better understanding and interpretation of the information of the scan data.

For the rough survey on the Noor Wali House the KAU group started to redraw the corrected floor plans digitally, and produced detailed plans of selected roshans and wooden walls. The main facade of the house and the front rooms of the fourth floor were scanned in 3D.

Week four was used to finalise records, compile all data and information and check the completeness and to prepare a presentation.

A public final presentation was prepared and held in the well known Naseef house (an object renovated and used as a museum in the centre of Al Balad), with participation of the house owner families and KAU faculty members and random audience of tourists and inhabitants of Al Balad.

\section{PROCESS OF THE CROSSCULTURAL INTERDISCIPLINARY WORK}

Although the program of the workshop has been implemented successfully before with other universities (e.g.: Cairo, Egypt or Baku, Azerbaijan) the schedule has always to be adapted and refined.

Communicational issues and wrong interpretation of requirements led to coordination problems. But with intense discussions and a lot of flexibility on both sides everything could be solved. Still the alterations of program and schedule on site were time consuming.

A very important subject for this training was the work of the VUT staff, consisting of 6 women (the male colleague gave the introduction into the anthropological approach in the first week and did not participate in the practical part of the training) working with the male staff and students of the KAU. Possible concerns from both sides were eliminated during the first meeting at the Baladia. For the work within the object the owner of the Al Nawar house granted permission to work without the abayah, a black long coat, the mandatory clothing for women outside their homes. This was great relief for the hard labour of building survey in the hot and humid climate.

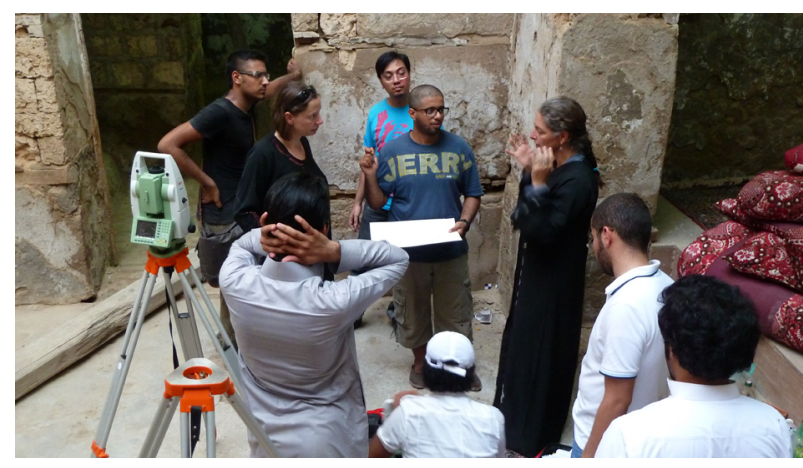

Figure 5 An unusual picture for Saudi Arabia

For the KAU members the interdisciplinary aspect and the work on site was very new. In an iterative process a part of the students could manage the situation and dedicated themselves to the interdisciplinary process and the intense discussion with the objects. The increasing engagement of the students with the subject resulted in a rising awareness of the qualities of the traditional architecture and historic urban patterns of Al Balad. As the staff of the KAU is not used to work on site with the students the involvement of the professors was focussed on scientific discussions.

\section{CONCLUSIONS}

For the detailed design of a training in building archaeology it is very important to have extensive information on the external preconditions on site.

Besides knowledge of the architecture information about the society, administrational matters and the educational level of the students to be trained have to be investigated in detail. This will provide a base for a successful educational program.

If, like in our case, the aim of the workshop is also to create data, material and information for research it is recommended to involve more staff or use more time, if possible.

For the TRABASA project the course training was very successful for a fourth of the participating students. Their engagement and enthusiasm allowed to complete the research for the Al Nawar House. This data is providing an useful base for future studies and also the possibility for the restoration or the design of an adaptation of the building for modern needs.

Furthermore the project and the training aroused the interest of Saudi staff and students for their own heritage. Some of them even brought their families to Al Balad and transferred their findings and information.

This development gives hope for the survival of the Saudi Arabian architectural heritage that is unique in its way and would provide interesting solutions concerning sustainable use of construction material and indoor climate.

In that way the engagement with the workshops on building archaeology provide an important tool for the transfer of knowledge and gives an impulse for the discussion on the cultural heritage.

\section{REFERENCES}

Adas, A., Eissa, M. A., 2010. GIS Applications for Documentation of Historical Jeddah Monuments, King Abdul- 
Aziz University Bulletin: Environmental Design Sciences, Saudi Arabia.

Bokhari, A. Y., 1978. Jeddah: A Study in Urban Formation, Ph.D. Thesis, Graduate Faculty of the University of Pennsylvania, USA.

Bokhari, Abdulla Y., 1983. Conservation in the Historic District of Jeddah. In Adaptive Reuse: Integrating Traditional Areas into the Modern Urban Fabric. Margaret Bentley Sevcenko, (ed). Cambridge, Mass.: MIT Laboratory of Architecture and Planning, USA.

Buchan, J., 1996. Jeddah Old and New, Stacey International, London, GB.

Doughty, Charles M., 1979: Reisen in Arabia Deserta, Wanderungen in der Arabischen Wüste 1876-1876, DuMont, Köln, Germany (first published Cambridge 1888).

Greenlaw, J.-P. (1995). The coral buildings of Suakin: Islamic architecture, planning, design and domestic arrangements in a red sea port. London, Kegan Paul International, GB.

Harrow, L., Larkin, C., 1984. City of the Red Sea, David Howell's Jiddah, Scorpion Publishing Ltd., London, GB.

Herbig, U., 2012. Interdisciplinary Approaches to the Built Heritage and their Role for World Heritage Sites Research \& Heritage: Researchpapers on Architectural Heritage/ The Saudi Commission for Tourism and Antiquities, Dammam, 1434H, 2012, page 263-285

Jäger-Klein C., 2012. On search for identity - Potentials of Domestic Building Traditions in Saudi Arabia in: Intar Journal, Vol_03_2011: Adaptive Reuse in Emerging Economies, Department of Interior Architecture, Rhode Island School of Design, Providence, USA.

Jenaideb, A., Eissa, M. A., 2009. Digital Modeling in Traditional Architecture Learning: the method and benefits. In Digitizing Architecture: Formalization and Content: 4th International Conference Proceedings of the Arab Society for Computer Aided Architectural Design, 153-162. ASCAAD. Manama, The Arab Society for Computer Aided Architectural Design, Kingdom of Bahrain.

Khan M., 1981. Jeddah Old Houses: A Study of Vernacular Architecture of the Old City of Jeddah, Saudi Arabian Council for Science and Technology, 12 pages, Saudi Arabia.

King, G. 1998, The Traditional Architecture of Saudi Arabia, L.B. Tauris \& Co Ltd., London, GB.

Krause, R. F., 1991. Stadtgeographische Untersuchungen in der Altstadt von Djidda, Dümmler, Bonn, Germany - KSA.

Llewellyn-Jones, R., 1995. The coral city of old Jeddah - Saudi Arabia, in: The Architectural Review, Vol. 198, No. 1183, pp 81-83, Emap Construct, London, GB.

Matthew, R., 1979. Jeddah: Historic Area Study, Stage Two, Recommendation for the architectural design demonstration $s t u d y$, Ministry of Interior (Municipal Affairs), Riyadh, KSA.

Mayer I., Toubekis G. et al., 2008. Laser Scan Measurement of the Niche and Virtual 3D Representation of the Small Buddha in Bamiyan; in: Proceedings of the 35th International Conference on Computer Applications and Quantitative
Methods in Archaeology (CAA). Germany, April 2-6, 2007. Kolloquien zur Vor- und Frühgeschichte, Vol. 10, Dr. Rudolf Habelt GmbH, Bonn, ISBN: 978-3-7749-3556-3.

Mayer, I., Scheiblauer, C., 2011. Virtual Texturing In The Documentation Of Cultural Heritage - The Domitilla Catacomb In Rome, in: XXIIIrd International CIPA Symposium, CIPA, ISPRS, Czech Technical University in Prague and Czech Society for Photogrammetry and Remote Sensing, Prag, ISBN: 978-80-01-04885-6, 8 pages

Oliver, P. (Ed.), 1997. Vernacular Architecture of the World, Vol.2, p. 1443-1460, Cambridge University Press, GB.

Pesce, A., 1976. Jiddah Portrait of an Arabian City, Falcon Press, London, GB.

Raguette, F., 2003. Traditional Domestic Architecture of the Arab Region, American Univeristy of Sharjah, Edition Axel Menges, Germany.

Russel, J., 1981. Jeddah Renewal, in: The Architectural Review Volume CLXIX Nr. 1010, pp.217-222, Emap Construct, London, GB.

Shihabi, B., 2004. Architecture in Saudi Arabia - A Wide Angle View, in: Abed, Jamal (Ed.): Architecture Re-introduced: New Projects in Societies in Change, p.59-61, Geneva: The Aga Khan Award for Architecture, $\mathrm{CH}$.

Sieghartsleitner, A., 2010. Traditionelle Bauformen im Westen Saudi Arabiens, Diploma Thesis, Vienna University of Technology, Department for History of Architecture and Building Archaeology, Vienna, Austria.

Styhler-Aydın, G., Mayer, I., 2012. 3D Laser Measurement as Part of an Integrative Building Survey for the Recording of Built Heritage; Invited Paper at: 17th International Conference on Cultural Heritage and New Technologies, Vienna, $05.11 .2012-07.11 .2012$, in print

Toubekis, G., Mayer, I., Döring-Williams, M., Maeda, K., Yamauchi, K., Taniguchi, Y., Morimoto, S., Petzet, M., Jarke, M., Jansen, M., 2009. Preservation and management of the UNESCO world heritage site of Bamiyan: Laser scan documentation and virtual reconstruction of the destroyed Buddha figures and the archaeological remains .In: Takase, Yutaka (Ed.): 'Digital Documentation, Interpretation \& Presentation of Cultural Heritage' , CIPA Symposium , 11 - 15 Oct. 2009 in Kyoto, Japan

World Heritage, Special Issue, 2011. World Heritage of the Gulf Countries; no. 60, June 2011, UNESCO - Division of Public Information, Paris, France. 